To appear in Crowther, T. and Mac Cumhaill, C. (eds.) Perceptual Ephemera. Forthcoming Oxford University Press

Please cite published version

\title{
Nonsense and Visual Evanescence ${ }^{1}$
}

\author{
Clare Mac Cumbaill
}

\section{$\$ 1$ Preamble}

We can say that things 'look see-through' - a crystal, a chiffon sleeve - and that they 'look transparent' - for instance, clear water. But is it intelligible to say that something 'looks invisible'? It might be thought that a philosopher of perception should have nothing to say about what cannot be seen - the invisible - and, further, that whatever is invisible, or insensible, cannot be said to 'look' that way. But there are contexts in which it seems that 'looks invisible' statements can be intelligibly used.

Fairytale

To the wise, the Emperor's new clothes look golden. To the foolish and incompetent, they 'look invisible'.

\section{Windowpane}

A pane of glass is polished to perfection. No glimmers or glints are discernible. There are no glittering lines to give away the presence of an edge. The windowpane 'looks invisible'.

For the philosopher of perception in the grip of her favourite theory, there is nothing to say about such statements other than to remark on their nonsensicality - or on the foolishness and incompetence of those who use them. Such confidence may stem from a range of assumptions about what can be seen - visible colour and shape - together with a conception of how we should understand the nature of looks: if looks are constituted by visible colour and shape nothing can 'look invisible'. But why should we care if statements that we find intelligible when used on some occasion, turn out to be nonsensical when viewed through the theoretical prism of some bit of philosophy? One response is that we need not care at all. Such statements are to be ignored. We keep the philosophy in denouncing the appearance of intelligibility. In this paper, I explore a different response by introducing a phenomenon that is so far untheorized in philosophy of perception: what I shall call visual evanescence.

As I explain, the phenomenon of visual evanescence helps create conceptual room for a treatment of looks statements not explicit in the contemporary literature, one which takes its cue from the philosophy of perception of G.E.M. Anscombe ${ }^{1}$ as well as the treatment of concepts found in Peter Geach's Mental Acts. ${ }^{2}$ For Geach, a concept is a capacity to use an expression in a judgment, where concepts are subjective capacities that may be more or less sophisticated in having more or less structure. On this view, a perceiver who is able to use the expression 'invisible' in judging that she is well-hidden may not be able to use it of figures on the horizon that she cannot discern, or of particles in Brownian motion. Her grasp of the concept may be 
purely phenomenalistic - it may be understood simply in terms of not seeing. But there are different ways of not seeing and her concept of the 'invisible' - her capacity to use that expression in judgments - may not extend to capture all those ways. In contrast, a perceiver that can use the expression 'invisible' in conjunction with 'looks', where 'looks' introduces a form of description - a description that has application in the current sensory context - possesses a concept that has a degree of internal complexity, as well as a 'background' or network of supporting concepts. Such a perceiver possesses the concept of a basic visible property - of colour and shape. She has mastered the use of 'looks' as introducing a gloss on 'what is seen', where 'what is seen' can be offered in response to the question 'what do you see?'. She manifests self-consciousness in being able to respond to that question, typically, in English, using the firstperson pronoun. She has learnt that the direct object of the sensation verb can be used to report the 'seeing' of not only of 'material objects' of sensation, as Anscombe calls them, but 'intentional objects' of sensation too. Both 'objects' are to be made sense of grammatically - they are direct objects of the sensation verb and do not pick out any kind of entity. Nonetheless, such a perceiver will have a naïve ontology of experience in being able to use such description intelligibly. She knows that 'what is seen' typically goes beyond the visible - we see bicycles made in China, people who skipped breakfast. She knows that 'what is seen' - flat tyres, purple scarves - can be seen by perceivers like herself. She knows that the colours of things fade, that she is apt to mismatch the colours of garments, and that some things of which we have experience are essentially perceptual - clothing, for instance.

In the first part of the paper, I set out the phenomenon visual evanescence and I counter some early scepticism. I then set out the challenge that 'looks invisible' poses for two ontological treatments of the nature of looks - sensationalist and objectivist treatments, as I call them. This in turn helps explain the relevance of the charge of nonsensicality and the temptation to make it. Finally, I make fully explicit the phenomenology that renders intelligible statements of the sort 'looks invisible'. Something can be said to 'look invisible' when one sees or appears to see the entirety of the space that the 'invisible' thing occupies. Such a space 'looks empty' while being full. I close by spelling out some lessons from evanescence and I begin with some history.

\section{\2. Visual Evanescence}

In 1896, Abbott H. Thayer, so-called 'Father of Camouflage' attended the annual meeting of the American Ornithologists' Union at Harvard Zoological Musuem. Thayer was there to demonstrate a phenomenon he had set out early that year in a paper published in the Union's journal, The Auk. Naturalists have long recognised mimicry - the fact that the colouration of animal bodies tends to mimic some other visible pattern; bark, lichen, dead leaves on a forest floor. But Thayer's 'newly discovered law', he claimed, rather than making the animal look like something else, makes it "cease to appear to exist at all". The italics are his."

The 'law' Thayer claims to have discovered (now called 'Thayer's Law) pertains to the fact that the dorsal part of the body of many animals is darker than the ventral part. Such animal bodies are counter-shaded. In the paper, he illustrated the effect of such variegation in colour with an inksketch: 


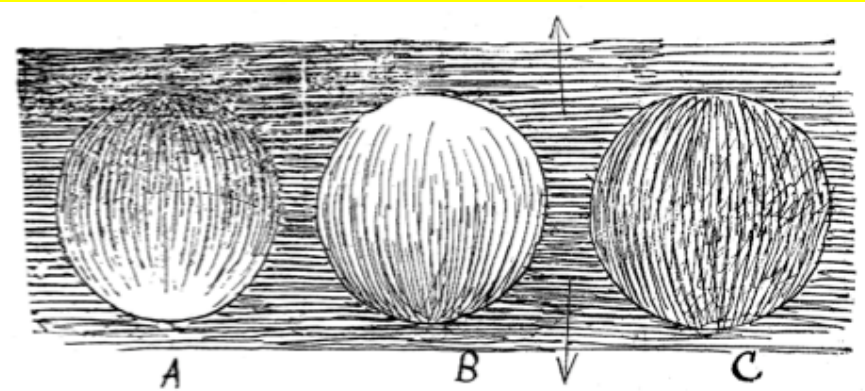

Figure 14.1: From A.H. Thayer (1896, p.125) Image out of copyright.

Sunlight typically falls on the dorsal part of the animal - "those parts which tend to be most lighted by the sky's light" (p.125) - while the ventral part is bathed in darkness (B). The effect of counter-shading or 'nature's paint', shown in A, is to 'balance out' this uneven pattern of reflectance, a pattern typically displayed by solid bodies, so as to yield an illusion of monochrome flatness (C).

Thayer's 1896 demonstration was intended to make plain the phenomenological consequences of countershading. In front of the audience assembled outside the museum, he retrieved a number of sweet potatoes from a sack and, mounting them on wire stilts, placed them in the noon sunlight. Then, using white oil paint, he carefully 'counter-shaded' the lower and underside of some of the potatoes. The result? Those that were 'countershaded' disappeared completely from view or, as I will put it, they visually evanesced. ${ }^{4}$

The image below, first published in Thayer's 1908 Concealing Colouration in the Animal Kingdom, shows a photographic record from another demonstration. The original caption reads 'two birdshaped models - the one on the left monochrome, the one on the right obliteratively shaded' (my emphasis, Thayer 1908, p. 250).

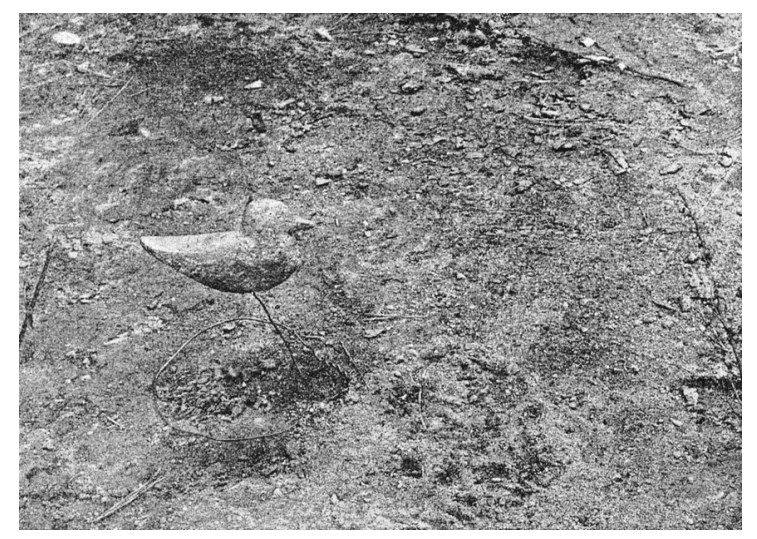

Figure 14.2 From G. Thayer (1908, p. 250). Image out of copyright.

Two ducks then are purported to be the subject of the photo, though only one has been countershaded. This suggests a third case to add to Fairytale and Windowpane.

\section{Evanescence}

The duck on the right 'looks invisible'.

In his paper Thayer in fact describes the perceptual effect of countershading a little differently: 
The result [viz. of countershading] is that their gradation of light and shade, by which opaque solid objects manifest themselves to the eye, is effaced at every point, the cancellation being as complete at one point as another....and the spectator seems to see right through the space really occupied by an opaque animal. (1896, p. 126).

Later he notes that the patterns on the animal are: "a picture of such a background as one might see if the animal were transparent" (p. 128). Thayer's practice of using stencils partly recapitulates this phenomenology. Stencils were used as a diagnostic to isolate the 'background' that would require 'picturing' at a particular location so as to effect visual evanescence. If the cut-out region were filled with a counter-shaded animal, the animal would seem to vanish.

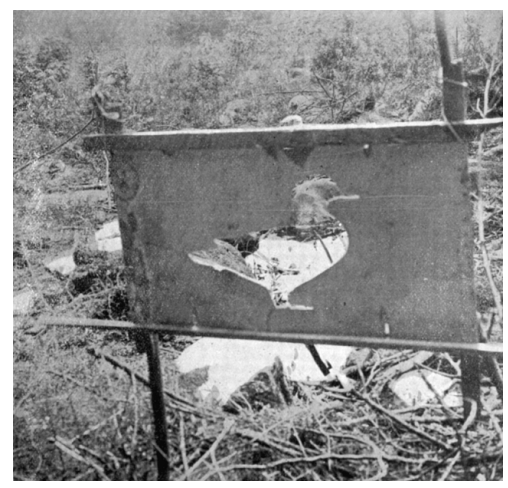

Figure. 14.3. Stencils used as 'background picturing' diagnostic. From Thayer (1918), reproduced in Behrens (2009, p.500). The original caption reads: 'A brook scene photographed through a duck-shaped stencil'. Image out of copyright.

The archives of his work at the Smithsonian Institute contain thousands such stencils.

What little mention of camouflage there is in the recent literature in philosophy of perception has tended to focus on background picturing, or mimicry, alone - proceeding, that is, without consideration of countershading. For instance, Susanna Siegel introduces us to Franco. Franco likes doing stunts in the sky and when painted blue, to a perceiver S:

Franco...is like a chameleon: he blends in with his surroundings to the point where he is, to $S$, indistinguishable from them. If Franco were painted a different color, or if instead of hanging still he moved around.....he probably would bring about a change in $\mathrm{S}$ 's visual phenomenology, and S would be able to see him. But the fact remains: $\mathrm{S}$ does not see him in the world in which he is painted blue and hangs still. (2006, p. 434).

The surface of Franco matches the sky, in this case through a form of occlusion, namely with blue paint. In this case then, merely matching the background (and hanging still) is sufficient to realise the function of camouflage - to avoid being seen. Notice, however, that in Thayer's 1908 document above, the duck on the left is the same colour as the dirt on which it stands. It nonetheless shows up in the photo. Mimicry, or mere 'background picturing' then is not sufficient to effect evanescence, and perhaps our reluctance to wholly endorse Siegel's conclusion is attuned to this fact. Since we can't visually discriminate Franco, we might agree that he is not seen. If pressed, however, we might just as likely reverse our opinion - after all, Franco's surface contributes to our visual phenomenology. Anscombe's distinction between material and intentional objects of sensation as outlined in her difficult (and for some mysterious $^{5}$ ) 'The Intentionality of Sensation: A Grammatical Feature' helps makes sense of this reversal. I sketch this briefly as a way of motivating the challenge that Evanescence poses, at least 
insofar as it appears to supply a context in which the use of 'looks invisible' is intelligible. I consider Fairytale and Windowpane much later, in $\$ 5$.

On Anscombe's grammatical treatment of verbs of sensation, the direct object of the verb can be given a material or intentional reading in a way that closely, if not entirely, mirrors intentional description in philosophy of action. While many descriptions may truthfully apply to an event that is an action, only some of them are intentional descriptions, descriptions 'under which' the person is acting and which specify what she is doing - what she knows she is doing without observation; without having to check or infer from what is happening. Likewise, though many descriptions may truthfully apply to the variety of things and events that a perceiver sees, only some of them are descriptions under which the perceiver sees what is seen. Such descriptions are of the sort that the perceiver might give in response to the question: 'What do you see?'

Since S would not return 'Franco' to the question 'What do you see?', nor even 'a man painted blue', we can assume, with Siegel, that S does not see Franco. Even so, since 'a patch of sky' is seen at the place where Franco is in fact suspended - where here 'a patch of sky' is the intentional object of the sensation verb - it seems that we can, after all, allow that $\mathrm{S}$ sees Franco. We can say that $S$ sees Franco in that she sees, at a place, 'a patch of sky' which is in fact ${ }^{6}$ Franco painted sky-blue and hanging still.

Evanescence does not so easily admit this intentional/material cleavage. The subject of the putative experience - the visible animal body - through having a peculiar visible profile, one which I will characterise in $\$ 3$, disappears. It evanesces. But this being so, there is, it might be thought, no appearance to speak of, no thing to see. Rather, if there is any description at all 'under which' the animal seen 'is seen', it is, perversely, something akin to that given by Thayer above, and which, some forty years later Zoologist Hugh Cott, in his landmark Adaptative Colouration in Animals, reframes approvingly:

In the words of A.H. Thayer, the effect of the obliterative gradation of light and shade is 'to render the creature's actual surface unrecognizable as the surface of any object or objects of the immediate foreground, causing it to pass for an empty space through which the background is seen' (underlining mine, 1940, p. 37, here quoting from Thayer 1909)

We have allowed that Franco is seen under the description 'a patch of sky', But can the evanescent animal body really be 'seen' under the description suggested by Cott? Can it be 'seen' under the description 'empty region'? It seems it can't. While we can make sense of Franco passing for a 'patch of sky' and hence of our seeing him in that we see 'a patch of sky', we cannot make sense of our seeing the evanescent animal body in that we see an 'empty region' at the place at which the animal is located. This does not mean however that the question 'what do you see'? is, as the Wittgensteinean might put it, 'refused application', for one can intelligibly respond 'I see nothing'. Compare: 'Nothing' is an intelligible answer to 'what do you have in your pockets?' But the question is refused where the response is 'I have no pockets!? Similarly, saying 'I have my eyes closed' or 'I am not looking' is to refuse the question 'What do you see?' 'I see nothing' does not. The perceiver does see. It's just that she sees nothing at the place at which the visible animal body is. This hints at the distinction with the Franco case. A parallel with the case of action helps draw this out further.

By waving her purple scarf, Mary catches Joe's attention. In that she is waving her scarf, she catches his attention. Here the 'in that' locution should be read as applying to things that Mary does. This being so, although it is true that the air in the vicinity of the scarf is being moved about as a result of Mary's scarf-waving, 'moving the air' isn't a description under which Mary is 
acting. It is not the case that Mary is moving the air in that she is waving her scarf. The case of Franco has a similar 'in that' explanatory form or structure. In seeing the patch of sky, it is true that $\mathrm{S}$ sees Franco. Though 'Franco' isn't the intentional description under which the thing seen - Franco - is seen, $S$ sees Franco in that she sees a patch of blue. Evanescence is different. It cannot be said that $S$ sees the animal body in that she sees an empty region. The animal body evanescing at a place and time is rather more like the movement of the air. How so?

The animal body evanesces at a time and place because a biologically-apt perceiver is exercising her capacity of sight at that time and place (just as the air moves about because Mary is excitedly waving her scarf). This explains why the question 'What do you see?' still has application. I say a more about the mechanisms behind evanescence in $\$ 2$ - this will help to waylay early scepticism concerning the very plausibility of Evanescence. For now, let us probe a little further the idea that the 'in that' locution, and hence the intentional/material distinction, does not apply so readily in cases of evanescence.

For Anscombe, part of the concept of seeing is that one can see sensible things at places, things that are available for other people to see at those places, the character of which is hence up for discussion. Her under-cited 'The Subjectivity of Sensation' spins from consideration of a single case which recognises this: "Doctors match blood samples with colours on a scale in order to judge how far someone is anaemic" (SS, p.44). The doctors are assessing how far someone is anaemic in that they are matching the colour of a blood-stained swatch with a colour on a chart. But "there is such a thing as competence" (ibid.), says Anscombe, and the doctor may doubt his acuity and call on an assistant to check his judgment. That the doctor calls on his assistant shows that he assumes not only that the assistant can see whatever colours be, the doctor, sees - the esse of colours is not then conceived to be their percepi - but also that the relevant objects of sight the colours of the swatch and chart - are somewhere and so are available to be seen by other perceivers.

In the case of evanescence, I have said that we cannot plausibly say that $S$ sees the visible animal body in that she sees an empty space. We can now say why. Unlike the Franco case, $S$ does not see anything sensible at a place that, by her lights, would be available to be seen by other perceivers exercising their capacity for sight. For instance, based on what she sees - nothing at a place - she cannot call on anyone else to look at that ${ }^{8}$ And this is so, even if it is the case that the animal body is in fact seen by other perceivers. There is, then, no plausible construal on which we can deploy the expression "see" to express the judgment that $S$ sees the animal body in that she sees an empty region'.

Anscombe describes the 'material use of the sensation verb' as a use which demands a material object of the verb - it cannot give a merely intentional object.' As such the 'in that' relation which holds between the intentional and material object and which is akin to the kind of calculative order that exists in the case of intentional action (in that Mary is waving her scarf, she is catching Joe's attention) can only apply in such material uses. The perceiver herself, Mary say, must said to see the relevant material object of sight, and this is the case even if the descriptions under which it is seen are vague and indeterminate. Cast differently, the first-person character of the concept of seeing necessitates that Mary "see" something sensible in a sense that would enable her to respond to the question "What do you see?" We have noted that saying "nothing" is not to refuse the question - Mary is exercising her capacity to see. Even so, Mary cannot be said to see the evanescent animal body in that she sees an empty region. This helps motivate the challenge of visual evanescence insofar as it provides a context in which, as I claim, the use of "looks invisible" is, if perversely so, intelligible. 
Thayer's demonstration required people to look at the visible objects that he was diligently countershading - sweet potatoes and decoy ducks. His audience outside the museum knew that visible bodies were present, bodies which thereafter disappeared and came, it might be said, if contestably, to "look invisible". The question I want to probe is how can anyone intelligibly say so. If no visible thing is seen, either intentionally or materially, and the perceiver claims to see instead an empty region, is the perceiver not speaking plain nonsense in saying that the thing which they do not see "looks invisible". The same point can be put another way. "What do you see?" has application. The answer is nothing. So how can nothing intelligibly be said to look any way? I explore this charge in the second half of the paper. First, I dispense with some early scepticism, as well as setting out in what sense evanescence is more akin to the moving of the air on the occasion of scarf-waving.

\section{\3. Early Scepticism}

Though the first premise of this paper is that we take the descriptive phenomenology of field theorists like Thayer and Cott seriously, there will, of course, be philosophers who are happier to rely on their own perceptual histories. A different, less methodological worry, may relate to Thayer's photographic document - is it genuine? I leave this aside. Instead, I focus on the simple incredulity that might attend the idea that an opaque, visible, solid body can 'pass for' an empty region at all. In this section, I offer a brief, empirical excursus so as to allay early scepticism. This helps explain what goes on when a biologically-apt perceiver is exercising its capacity to see, at a time and place where an 'evanescent' animal body is located - a body with a visible profile that is apt to evanesce for such a biologically-apt perceiver. This in turn will help sharpen my analysis of the putative origin of the apparent nonsensicality of "looks invisible" in $₫ 4$.

Recall Thayer's descriptive phenomenology: When an animal body evanesces "the spectator seems to see right through the space really occupied by an opaque animal", where the patterns on the animal's surface are "a picture of such a background as one might see if the animal were transparent" (p. 128). This description suggests a way of addressing the sceptical worry straight off. The opaque animal body looks see-through or transparent. As I will explain, there are a number of features of the visible of surface of the animal body that can be recruited to explain this descriptive phenomenology. First, transparency.

Psychologists of transparency distinguish between regions in the visual array that form ' $\mathrm{X}$ junctions' and those that form 'T-junctions'. X-junctions are defined by the presence, in the image, of four contiguous regions with specific intensity relationships which elicit the perception of transparency (see Stoner 1999, p.846).

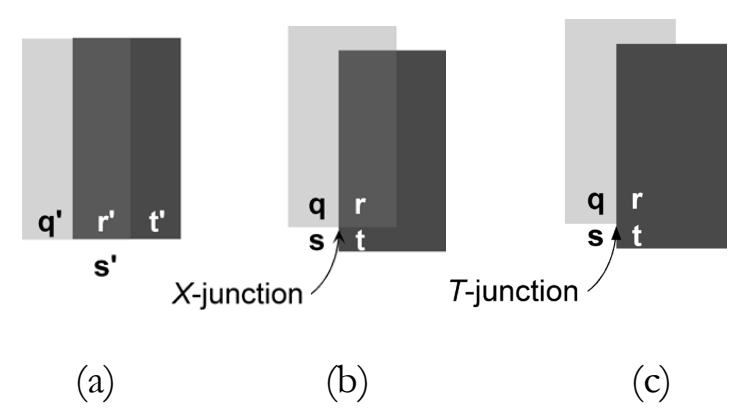

Figure 14.4. From Stoner (1999), in Wilson, Robert A., and Frank C. Keil, (eds.), The MIT Encyclopedia of the Cognitive Sciences (MITECS), Figure 1 (a \& b), p. 846: X-Junction; Figure 2 (c), p. 846: T-Junction, C 1999 Massachusetts Institute of Technology, by permission of The MIT Press. 
To illustrate, notice that the regions labelled ' $r$ ' ' and ' $r$ in (a) and (b) above have the same luminance value. In (b), however, the intensity values of adjacent regions and their distribution differ: an Xjunction is formed. Such a constellation of intensity values leads the visual system to infer that two surfaces in different depth planes are present, the composite luminance values of which yield the value of ' $r$ '. In the psychological literature, this 'colour split' (Casati 2009) is called 'scission.' ${ }^{10}$

It might be wondered whether a scission-type effect is operative in cases of animal evanescence. Two considerations suggest it might be. The evolved effect of background picturing is to ape the appearance of the kinds of surfaces that would tend to present behind the animal - this is what Thayer's stencils teach. There is seeming if not genuine spatial ordering. Second, transparent media typically have homogeneous luminosity profiles - they are film-like. But, as Thayer's sketch illustrates, this is precisely the effect that countershading induces; it renders the visible surface of the animal luminously homogenous or filmic.

A plate from Cott (1940) illustrates this phenomenology.

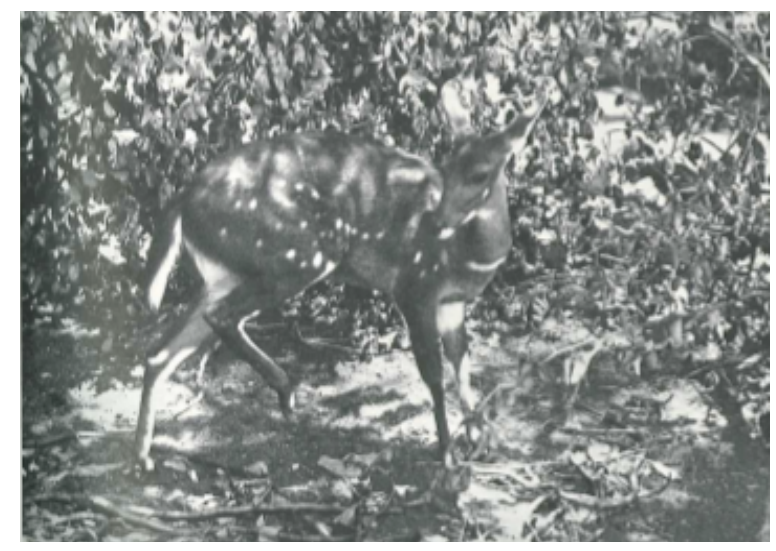

Figure 14.5. 'Bush Buck', from Cott (1940, p.48).

Image courtesy of the Cott Archives, Cambridge Zoological Museum.

The 'bush buck' is countershaded. White spots, mimicking dappled light, are scattered across its body, which thereby seems to possess a holographic, de-substantiated quality that may visually strike one as tending toward evanescence - the region the deer occupies may be apprehended as a region through which the background is visible, but which, like that background, is in shade. Even so, appearing perceptually transparent does not yet involve "ceasing to appear to exist at all" and this, recall, was Thayer's boast. What more is needed?

Perceptual transparency requires the spatial ordering of two surfaces in three dimensions (at least in ecological situations). Two surfaces then are seen. Borrowing some familiar idiom from pictorial aesthetics, there is, we might say, a kind of twofold seeing. In the pictorial case, the notion of 'foldedness' applies since despite pictorial experience being twofold (one sees the surface of the canvas and the objects 'seen in' the surface), there is only one opaque, visible surface present - that of the canvas. ${ }^{11}$ Evanescence, though close to the pictorial case, is different. 
Like the canvas, there is, in cases of evanescence, only one surface present - the surface of the body of the cryptically coloured animal. In cases of perfect or complete evanescence however, the elicited perception must not, after all, be twofold- that is, the animal must not look transparent. Rather, in the manner of a perfect trompe d'oeil where the surface of the canvas is completely visually elided, the animal body must evanesce entirely. The elicited perception must, let's say, be single-fold. But this suggests what must be added to 'looking transparent' in order to 'look invisible': the elision of all X-junctions at a place, an effect that various sorts of differential blending patterns have adapted to realise. ${ }^{12}$ 'Disruptive' markings, for instance, are those that have been selected to erase, blur, or 'break up' and so 'rupture' the visible boundary of the creature; the "tell-tale appearance of form" (Cott 1940, p. 48). ${ }^{13}$
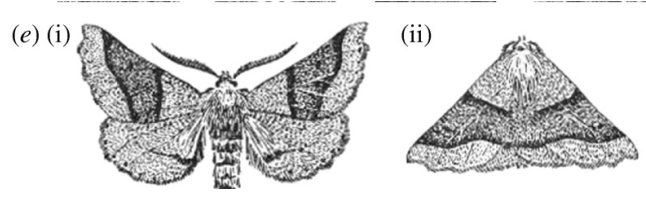

Figure 14.6 Disruptive 'marginal' patterns on the Scalloped Oak moth (Cott, 1940, p.76). Notice that the markings link body parts that are otherwise spatially separated. Once conjoined however, they sketch the outline, and so appearance, of something else: bark or lichen. Image courtesy of the Cott Archives, Cambridge Zoological Museum.

There are then a number of visible features of the visible surface of the animal body which contribute to the possibility of evanescence at a place. The animal is counter-shaded, it 'pictures' its canonical background, and displays differential blending and disruptive coloration that leads to the elision of any X-junctions at a place. Such are the mechanisms that realise the function of camouflage. The biologically-apt perceiver does not "see" the animal in crypsis, where "see" in its material use demands a material object of the sensation verb. Nonetheless, it remains the case that in exercising her capacity of sight at that place, a scission-like process occurs, a process we should assume is typical for perceivers of her kind. We might say that it is just the case that this is what happens when the capacity is exercised at that time and place, just as air-moving is what happens when Mary waves her scarf.

Naturally, this explanation is only a philosopher's sketch and a speculative one at that. More important, however, is what it illustrates. The explanation I have offered adverts to basic visible properties, those of colour and shape. Such properties are available to "see" at places. Since, however, we take it that the esse of colours is not their percipi - even though "we get to know" such sensible properties by seeing (IS, p.14) - and since we who understand the terms 'colour' and 'shape' have a non-phenomenalistic grasp of such concepts, we can make sense, once informed, of how it is that something with a structured, visible coloration pattern and shape can nonetheless visually evanesce and pass instead for an empty region. Evanescence is not mysterious from a mechanistic point of view. So why might we be reluctant to accept the intelligibility of 'looks invisible' reports? I explore the source of such resistance in the next section.

\section{\4. Nonsense}

Suppose, after Geach, that we treat a concept as a capacity to use an expression in a judgment. On this view, concepts are subjective capacities, for individuals will vary in the extent to which they can so use a given expression. A child that has a phenomenalistic conception of the visible has a phenomenalistic conception of the invisible. Young children hide in full view behind their 
hands. They may judge themselves "invisible", and even have a nascent conception of a visible thing as something can be known by sight (this is why they cover their eyes).

As we have noted however, a non-phenomenalistic conception of the visible is a requirement on the intelligible use of the sensation verb "see", the primary application of which is material. For what can be "seen", recall, is available to seen by others, even if it cannot be seen by someone (or anyone) on occasion, perhaps because it is too small, or too far away. ${ }^{14}$ Still, having such a nonphenomenalistic conception of the visible does not make complicit a non-phenomenalistic conception of the invisible, though happily such a grasp is not so difficult to come by. Every child after a certain age can characterise the invisibility that Windowpane captures: there are things that we can touch (or crash or walk into), and which hence are there, but which we cannot see. Those things are invisible, even when we are looking.

Frege claimed to describe 'the mind', not a particular mind. The Geach/Anscombe tack is similar, if slightly divergent. Though concepts, unlike Fregean Begriffe, are subjective, they are also human. A human concept is built up out all the uses that it has. The human concept of the invisible is thus made up of phenomenalistic uses and of those that are not. That the concept is used on an occasion, however, requires that its use on that occasion be intelligible. This is because intelligibility is a demand on the possibility of judging (and a concept, recall, is a capacity to use an expression in a judgment). Geach has it that a requirement on a thought counting as a judgment is that its content can be put into the oratio obliqua form. That is to say, its gist can be reported with a that-clause. But the gist of what does not make sense - nonsense - cannot be reported. I pick up this thought later. For now, a gloss on 'looks' both in its use as a sensory appearance verb and in its nominalised form.

Recent literature notes that the appearance verb 'look' can be used evidentially or nonevidentially, where this distinction likely to be pragmatic. In the evidential case, the sensation verb is used to gesture at sensory evidence for the adjective or adjectival phrasing applying to the grammatical subject, though without committing the speaker to the truth of the proposition that would be thereby be expressed. In the non-evidential case, the focus is rather on the sensory appearance of the grammatical subject - the way of looking the grammatical subject has.

Philosophers have also isolated different senses or uses of the appearance verb, notably the distinction between phenomenal, comparative and epistemic senses or uses of 'looks', a division due to Chisholm and after him Jackson, and which many contemporary philosophers have embraced. ${ }^{15}$ Whether such philosophers have succeeded in identifying different senses of the verb however, the taxonomy is indicative at least of a form of complexity in our use of the appearance verb. For expediency, I only jot these down.

The epistemic sense reports on how things look to be and is often followed by predicatival as if clauses. The comparative sense or use suggests a visible similarity between the grammatical subject and the content of the predicatival clause, and is often followed by predicatival like clauses. The phenomenal sense is said to be followed by expressions for 'phenomenal concepts' such as shape or colour, or distance relations. ${ }^{16}$ Martin (2010) argues that almost all uses are comparative, even in the absence of any explicit comparative markers. I briefly discuss his proposal later.

Added to this complexity in the use of looks is a tendency to use looks so as to mark an appearance/reality distinction, though, as Anscombe notes, in saying that something looks a certain way, the primary intended use of the appearance verb is to give a description that would be true of the thing seen. Here the range of descriptions is vast, but of those that narrowly describe 
basic sensory properties like colour and shape, since such terms describe properties that we get to know through sight, it follows that giving a true description is giving a description of the appearance that the thing has. Despite this we commonly look at, and describe, things that, as we may say, 'look' differently to how they are. Mary's scarf looks vermilion under streetlight.

Turning to the nominalised form, it should already be clear that the capacity to use the expression 'looks' in nominalised form - as in ' $x$ has a $z$-look, or a look of $z$ - requires a degree of conceptual sophistication. A non-phenomenalistic grasp on the concept of the visible is needed, as is an appreciation the 'respects' in which various visible things can be the same or different. Colour is one primitive respect.

Revisit the doctor's procedure. Says Anscombe:

Now why do we say the reds are the same....I suggest that there isn't exactly a reason, a justification. It is rather that our language just does go like that. Colours that keep on looking the same to the same eye, against the same backgrounds, and in the same light and orientation, are the same. (SS, p.47)

Colour is a respect in which things can look the same or have the same look, but there are manifold other 'respects', attention to which is often a matter of instruction or requires guidance. This partly explains why the use of looks locutions typically bas a point. We can describe how things look so that others can thereafter recognise the things described or come to know the appearance pointed out ('This one looks rotten' 'Let me see'). But sameness is not a matter of identity. Mary may mistake her meeting place with Joe, though the street-corner looks in all respects as he described it. Sometimes, we can get others to see what we see and which we may think is available to be seen, by reporting how things look to us.

Such happenings and reportings are quotidian and ordinary, but the use of 'looks invisible' is not. Still, Fairytale, Windowpane and Evanescence appear to be plausible scenarios in which its use is intelligible. Why then might the charge of nonsense compel?

Leave aside the thought that what cannot be seen cannot be looked at and assume a nonphenomenalistic conception of visible properties. As I will show, the difficulty is not so much with one's conception of the visible - though this, as we shall see, remains a factor - as with an appreciation of the notion of 'looks' which is ontological in flavour, together with what Cora Diamond characterises as a natural view of nonsense.

On a natural view of nonsense, nonsense is understood to issue from the concatenation of linguistic expressions, the meaning of each of which is fixed in isolation and which, when concatenated or strung together, leads to a kind of mismatch and so a breakdown in meaning, typically in the form of a category mistake. 'Caesar is a prime number' is a canonical example. Intelligibility then is settled at the level of the linguistic string, where the meaning of component terms is determined independently of the context of the use of the string and independently of the meaning of the sentence as whole. Caesar, a man, cannot be a 'number' - the predicate is, in Annette Baier's words 'unsuitable'. ${ }^{17}$

It is easy to guess at how 'looks invisible' might be deemed nonsensical on such a natural approach. I do that shortly. First, it is worth pausing to consider what kinds of things the expression 'looks' could anyway stand for. 
The simplest construal of the meaning of 'looks' is one on which looks are analogised to sounds and smells, something the nominalisation of looks makes seem natural. On this view, looks, like sounds and smells, are sensory individuals that are constituted by sensory properties, individuals that the word 'looks' might be thought to stand for. Call this a sensationalist construal of looks. On a sensationalist construal, and given a certain use, namely where the appearance verb is used non-evidentially to introduce an appearance (a 'look') which the predicatival complement specifies or glosses, it should be no surprise that 'looks invisible' should be found to generate nonsense. No sensory individual can lack sensory properties. Jackson's (1977) notorious analysis of the underlying logical form of the phenomenal sense of looks can perhaps be regarded as sensationalist in spirit (no sense datum can be insensible). ${ }^{18}$

The sensationalist construal of looks treats of looks ontologically - looks are sensory individuals or entities. An objectivist construal of looks, as I will call it, also recommends an ontological approach, one which, as I will show, is also apt to make inevitable the charge of nonsensicality, at least when yoked to a naturalistic conception of meaning. Recent work by MGF Martin might be read in this vein. ${ }^{19}$

On one way of reading Martin's parsimonious treatment of looks, looks are identified with basic intrinsic properties which objects anyway have - for Martin the observational properties of colour and shape - along with the non-observational property of visible solidity. Objects are conceived to have 'ways of looking' where a 'way of looking' is -

[s] ome aspect in which it resembles or fails to resemble any other object....The standard list of observational properties in the visual realm gives us a group of properties which are such that objects can be grouped as more or less similar with respect to them, and the presence or absence of which properties for visually perceptible objects are visually detectible....the various ways of looking it may share or contrast with other objects are just conjunctions or disjunctions of the observational properties it has. (emphasis mine, 2010, p. 206)

Together with this parsimonious ontology of looks, Martin advances a minimalist semantics for looks statements. Unlike those philosophers who harness the three-fold distinction noted earlier, Martin suggests that almost all non-evidential uses of looks statements are comparative. While the appearance verb in the non-evidential use introduces a 'look' understood in the parsimonious, non-sensationalist way sketched above, the predicatival complement that specifies that appearance is implicitly comparative. Martin's minimalist semantics is intricate. For instance, 'that coin looks elliptical' is excavated as:

$$
\exists s(\text { Has }(\text { that coin, } s) \wedge(\operatorname{Look}(s) \wedge \operatorname{SIM}(C(\text { 'elliptical', Look, } k),(\mathrm{s})))
$$

Here, $s$ refers to a state that the coin is in. Just as the coin, tuppence say, weighs a certain amount $-7.12 \mathrm{~g}$ - and just as that weight is a way that the coin is or a state that the coin is in, the coin also has a way of looking or a looks state, where this is also a way that the $2 \mathrm{p}$ coin is. Likewise, just as a metric - grams - specifies the weight of the coin, the predicate of predicates SIM provides a metric in the case of looks. The metric is a comparative. The coin looks relevantly similar to the way elliptical things look given a certain contextual restriction, $k . \mathrm{C}$, finally, designates a function which returns for the lexical item 'elliptical', on the execution of a certain psychological operation which Martin calls getting-the-characteristic, a set of characteristics or kinds of ways of looking given the contextual restriction, $k^{20}$ 
Adopting Martin's parsimonious ontology of looks, together with his minimalist semantics spells trouble for 'looks invisible', at least on a natural view of nonsense. Why? If looks are identified with basic visible properties, intrinsic properties that objects anyway have, and if 'looks' in the non-evidential use introduces the look of an object which the complement specifies and where the underlying semantics are as Martin proposes, then nothing, surely, can 'look invisible'. Even if 'invisible' can specify a metric which indicates a peculiarly negative way of looking - viz. all visually detectible properties are absent - it might be doubted that there is any characteristic which the function $\mathrm{C}$ would return that is associated with that negative way of looking. On either a sensationalist or objectivist account of 'looks' then, on certain uses and coupled with a natural view of nonsense, there is no way of making sense of the 'looks invisible' locution. The predicate is just 'unsuitable'.

There are other ontological treatments of looks which I do not consider, or even propose to mention here; for one, the idea that looks are to be identified not with the intrinsic properties of objects, but with manifestations of dispositions to appear in certain conditions. ${ }^{21}$ Instead I want to compare ontologically-motivated approaches with the grammatical approach that I draw from Anscombe's sophisticated philosophy of perception. The dialectical pairing of the sensationalist and objectivist mimics her opposition and reconciliation of the various insights of the mid-century ordinary language philosopher and earlier sense-datum theorists who are her interlocutors in the 'Intentionality of Sensation'. Even on a grammatical treatment, however, 'looks invisible' is not entirely straightforward to account for.

While on the ontological approach, the predicatival complement is understood, in the nonevidential case, to specify a look, where this is understood to have a nature (to be sensory say, or to be conjunction of observational properties), on the grammatical approach the appearance verb 'looks' introduces a form of description, namely one that applies to the object of sight, where this is the direct object of the sensation verb 'see'. Accordingly, the grammatical subject of the appearance verb is the direct object of the sensation verb, something that at once implicates the first person: we get to know how things appear by our seeing them. But in the uses of 'looks' that are primary - where the use of looks has a point, we might say - the assumption is also that the objects of sight, the appearances of which the description introduced specifies, are available to be seen at places by other perceivers. Intelligible uses of looks then will be those where the description introduced, be it comparative, evaluative or where the intended use is simply to describe the sensible appearance of the object of sight, will make sense to other perceivers. This approach allows us to consider seriously the intelligibility of 'looks invisible', without the prejudice, on which the natural view of the nonsensicality of 'looks invisible' thrives, of an ontological reification of looks. Nonetheless, we are not yet home and dry.

The grammatical subject of the appearance verb has been said to be the direct object of the sensation verb. But in all the cases I have conjured, though the question 'What do you see?' is not refused application, the perceiver cannot be said to see the thing that is said to look invisible. Further, in the case of Evanescence, we have denied that the perceiver can be said to see the animal in crypsis in that she sees an empty region. In the next section, I assemble the conceptual resources that I think invite a solution.

Diamond contrasts the natural view of nonsense with a Wittgensteinean/Fregean view whereby the meaning of a sentence cannot be determined by the 'meaning' of its working parts alone. Individual linguistic items have no meaning independently of the meaning of a sentence as a whole; the first word 'Caesar' in 'Caesar is a prime number' may not have the same meaning as it does in 'Caesar crossed the Rubicon'; 'is a prime number' may not mean what it does in '53 is a prime number'. If the sentence is nonsensical, rather, no part of it can be said to meaning 
anything - i.e. to mean what it does in another sentence that makes sense. The Geachian/Anscombian view is, I think, different again. A concept, recall, is a capacity to use an expression in a judgment, where a thought or utterance counts as judgment if its gist can be reported in oratio obliqua form. Nonsense then cannot be judged since its gist cannot be reported. On this view, then, intelligibility or making sense is conceptualised not at the level of the meaning of component parts or at the level of the sentence but at the level of speaker. The question is whether they are intelligible in what they say, think or judge to be the case at a context, such that the gist of what they say can be reported. ${ }^{22}$

So, can the scenarios I have conjured survive this proof of the nonsensical? Can their speaker be made intelligible? I think they can:

'The housewife judged that her windows were so clean that they looked wide open - you couldn't even tell that glass was there'

'The Emperor judged that his clothes looked invisible and that he, inter alia, must be incompetent'.

'The Harvard ornithologists judged that the decoy ducks had indeed "ceased to appear to exist" at the place at which the artist Thayer had placed them in the noon sunlight and painted them into evanescence'.

\section{J5. Looks invisible' domesticated}

I have suggested that a perceiver that can use the 'looks invisible' locution has a complex understanding of a number of concepts. In particular, it seems we should say that that such a perceiver has:

1. a concept of the visible as that which can be known by sight

2. a non-phenomenalistic conception of the visible such that she can grasp the possibility of visible things being seen at places by others, even if no one in fact ever sees them

3. a grasp of the use of looks as introducing a form of description that specifies the appearance of the object of sight, where that object, the direct object of the sensation verb, can be material or intentional

4. knowledge that "what is seen" typically goes beyond the visible - this is since material objects of sensation can figure as grammatical subjects in her looks locutions ('that bike made in China looks pricey')

5. a non-phenomenalistic conception of the invisible that extends to cover things as lacking the visible properties of colour and shape, such as in Windowpane.

Naturally, a perceiver can lack (1)-(5) for a perceiver can lack a concept of the visible and yet exercise the capacity for sight.

We are now in a position to domesticate Windowpane, Fairytale and finally Evanescence. 


\section{Windowpane}

The best reading of 'looks invisible' in the case of Windowpane is evidential. On the basis of the sensory evidence available, the windowpane looks to be invisible. No glimmers or glints are discernible. There no glittering lines to give away the presence of an edge. What kind of sensory evidence could lead to that supposition? The answer should now be obvious: the apparent perception of an empty region. The region 'looks empty', but is full ('The housewife judged that her windows were so clean that they looked wide open'). Recall too that the question 'What do you see?' is not refused. The perceiver sees an empty region. This, then, is the sensory evidence that warrants the attribution of the predication of 'invisible' to the grammatical subject. The grammatical subject can be said to be 'invisible' not just because the perceiver cannot see it, but because it is lacking the sensible properties of the sort that could be seen by others at that place.

\section{Fairytale}

Like Windowpane, we can imagine that the region that the putative clothes occupy also looks empty - we can, to borrow Thayer's idiom, 'see through those regions' to the apparently naked body underneath. Do the clothes thereby look to be invisible?

The story has it that only wise and competent could see the finery of the garments. It is not then assumed that the clothes are invisible in the manner of Windowpane, but only that they look that way. Fairytale, I suggest, invites, a non-evidential take on 'looks'. However, as I have argued above, an ontological treatment of the nature of looks makes the Emperor's alarm unintelligible. No look can look invisible. What the Emperor fails to see however is not a look, but his new clothes. And since clothes are typically visible - as I would like say they are essentially perceptible - the use of the appearance verb to introduce a form of description that glosses their appearance is warranted, as is, on this occasion, the use of the predicatival complement: they 'look invisible'. This suggests a way of overcoming the difficulty that I noted at the end of section $\$ 4$. The perceiver cannot be said to "see" the thing that is said to 'look invisible'. In what sense then can an object of sight figure as the grammatical subject of the appearance verb?

Compare: 'I am going for a walk' with 'I am going to fail the exam'. The former wears its intentionality on its sleeve; going for a walk is an intentional action. The latter, in contrast, is typically read as a prediction for the future. We need extra background to extract the intentional reading that one intends to fail the exam. ${ }^{23}$ I suggest that there are manifold concepts of ours that analogously wear their sensibility or perceptibility on their sleeve. Clothing is, appropriately in this case, a good example, but there are countless others: curtains, shopfronts, paintings, all kinds of cultural artefacts. Such items are essentially perceptible - they are designed or made to be perceived. But, accordingly, the using the appearance verb to introduce a gloss their appearance is warranted, even, I contend, when the description introduced is 'invisible'.

An ontological reading of looks cannot offer this result and, in part, this is because sensationalist and objectivist theorists alike are committed to a historically empiricist conception of the visible. On such a view, even if we see tomatoes and pine trees, what is basically visible extends only to what representationalist theorists of perception have elsewhere designated as narrow content: colour and visible shape. Rather than use the idiom of the representationalist, let us call the concepts of colour and visible shape 'thin concepts of the visible'. Our concepts of things that are essentially perceptible are, in contrast and at least typically, thick. ${ }^{24}$ 
How is Evanescence domesticated on this grammatical approach? We ought not read Evanescence on the model of Windowpane, I think. The animal body in crypsis is visible and elaborately so: it pictures the background of its natural habitat, is countershaded and displays differential blending patterns and even, sometimes, dissimulating stripes and images (butterfly wings for example often 'depict' the eyes of predators). Even so, when the animal evanesces at a place, the biologically-apt perceiver can be said to appear to see an empty region. This suggests some unity to the cases we have treated. In all cases, something can be said to 'look invisible' when one appears to see the entirety of the space that the 'invisible-looking' thing in fact occupies. ${ }^{25}$ In this sense, then, the space 'looks empty'. However, like Fairytale, and unlike Windowpane, in Evanescence the emphasis is not on the sensory evidence for the animal body being invisible - after all, the Harvard Ornithologists knew that the ducks, visible things, were there - but on its appearance at a time. I suggested earlier, though, that we ought not to say that the evanescent animal body is seen in that the perceiver sees an empty region. So, to revisit our puzzle, how can it be thereby said to 'look' anyway at all?

Like curtains and shopfronts, animal bodies are also essentially perceptible though we might not immediately conceive of them as such. Their superficial visible characteristics have been adapted under pressure of the fact that they are potential objects of sight not only for other creatures of their kind, but for certain biologically-apt perceivers, namely as prey. Though we don't typically conceive of animal bodies as essentially perceptible, we do however conceive of them as objects of sight in the sense that demands a material object. We do not, that is, think of visible animal bodies as merely thinly visible and as possessed of appearances that are only assemblies or mosaics of colour and shape. Instead, descriptions of animal appearances, such as the one borrowed from the National Geographic below, are typically rich in evaluative and activity terms:

Iguanas' stout build gives them a clumsy look, but they are fast and agile on land. They have strong jaws with razor-sharp teeth and sharp tails, which make up half their body length and can be used as whips to drive off predators. They can also detach their tails if caught and will grow another without permanent damage. ${ }^{26}$

But this explains the surprise of evanescence. Our naïve ontology of experience is such that we take "what is seen" to go beyond the basic visible properties that our 'thin' concepts of the visible (visual shape and colour) pick out. We take animal bodies to have a life beyond their superficial visible appearances. A bystander at Thayer's demonstration reported that the effect was "almost magical" (Boynton 1952, quoted in Shell 2012, p.16)

\section{$\$ 6$ Lessons from Evanescence}

In closing, I note two primary lessons that I see as arising from the philosophical picture I have tried to sketch.

First, if the account I have given is at all plausible, and if something can intelligibly be said to "look invisible" when the region it occupies "looks empty", we ought not to deny that empty regions are seen, for otherwise how could the occupied region look that way. A grammatical approach could certainly grant this much, though there is plainly a great deal that needs saying here. On the ontological conceptions of the visible that I have mentioned here however, it becomes genuinely difficult to grant that empty space is seen at all, or, if it is, then it is seen only indirectly: we see that regions are empty, or we see empty regions in virtue of our awareness of something else, the boundaries of the visual field for instance. ${ }^{27,28}$ 
Second, as might be expected, with the notion of the essentially perceptible comes an emphasis on norms of looking, as well as acting on 'what is seen'; on modes of conduct fitting to the presence of 'what is seen'. Sometimes there is a fitting way to look at and watch things that are essentially perceptible. Evanescence disrupts those norms in the case of the preying perceiver. Curtains do in the case of curious neighbours.

An emphasis on the essentially perceptible requires, further, an emphasis, not on the 'normal subject', the subject who is not hallucinating, or whose perceptual apparatus is somehow inadequate, but on the biologically- and culturally-apt perceiver. In some cases, it may require an ethnography of perception; a description of how we learn to look and notice and to pay attention, and how it is, the mechanisms by means of which, we may come overlook what is there to see - the nakedness of the fairytale Emperor for instance, his foolishness and incompetence.

\section{References}

Anscombe, G.E.M. (1957/2000) Intention. Harvard University Press.

Anscombe, G.E.M. (1965/1981) 'The Intentionality of Sensation: A Grammatical Feature', in Metaphysics and the Philosophy of Mind: Collected Philosophical Papers, Volume II, Oxford: Basil Blackwell, pp. 3-21

Anscombe, G.E.M. (1976/1981) 'The Subjectivity of Sensation', in Metaphysics and the Philosophy of Mind: Collected Philosophical Papers, Volume II, Oxford: Basil Blackwell, pp. 44-56

Behrens, Roy R. (2009) 'Revisiting Abbott Thayer: non-scientific reflections about camouflage in art, war and zoology'. Phil. Trans. R. Soc. B, 364, pp. 497-501.

Boynton, M. F. (1952) 'Abbott Thayer and natural history' Osiris, 10, pp. 542-555.

Breckenridge, W. (2007). 'The Meaning of 'Look”. PhD thesis. New College, University of Oxford. URL: http://www.wylieb.com/.

Brogaard, B. (2014). 'The Phenomenal Use of 'Look' and Perceptual Representation', in Philosophy Compass 9, pp. 455-468.

Brogaard, B. (2015) 'Perceptual Reports', in Mohan Matthen (ed.) Oxford Handbook of the Philosophy of Perception, Oxford: Oxford University Press, pp. 237-255.

Casati, R. (2009) 'Are shadows transparent? An investigation on white, shadows and transparency in pictures' Res, 56, pp. 329-335

Cott, H. B. (1940) Adaptive Coloration in Animals. London: Metheun \& Co. Ltd.

Diamond, C. (1981) 'What Nonsense Might Be' Philosophy 56(215):5-22

Geach, P.T. (1957) Mental Acts: their Content and their Objects. London: Routledge and Kegan Paul.

Genone, J. (2014) 'Appearance and Illusion'. Mind 123(490): 339-376

Glüer, K. (2013) 'Martin on the Semantics of 'Looks"' Thought 1, pp. 292-300.

Martin, M.G.F. (2010) 'What's in a look?', in B. Nanay (ed.) Perceiving the World. Oxford: Oxford University Press, pp. 160-225

Matthen, M. (2010) 'How Things Look (And What Things Look that Way), in B. Nanay (ed.) Perceiving the World. Oxford: Oxford University Press, pp. 226-255

Maund, B. (1986). "The phenomenal and other uses of 'looks"' Australasian Journal of Philosophy 64, pp. 170-180.

Newall, M. (2015) 'Is Seeing-In a Transparency Effect?' British Journal of Aesthetics, 55(2), pp. 131-156

Shell, Hanna Rose. (2012). Hide and Seek: Camouflage, Photography and the Media of Reconnaissance. MA: Zone Books MIT Press

Siegel, S. (2006) 'How does visual phenomenology constrain object-seeing?' 
Australasian Journal of Philosophy, 84(3), pp. 429-441

Richardson, L. (2010) 'Seeing Empty Space'. European Journal of Philosophy

Soteriou, M. (2013) The Mind's Construction. Oxford: OUP.

Stevens M., and Merilaita S. (2011) Animal Camouflage: Mechanisms and Function.

Cambridge: Cambridge University Press.

Stoner, G. (1999) 'Transparency', MIT Enclyclopedia of Cognitive Sciences. MA:

MIT Press.

Thayer, A. H. (1896) 'The law which underlies protective colouration' Auk, 13, pp. 124-129.

Thayer, A. H. (1918) 'Camouflage' The Scientific Monthly VII, pp. 481-494.

Thayer, G. H. (1908) 'The concealing colouration of animals: new light on an old subject' Century Magazine LXXVI, pp. 249-261.

Travis, C. (2015) 'Sufffering Intentionally?', in Campbell M. and O’Sullivan M. (eds) Wittgenstein and Perception. Oxford and New York: Routledge, pp. 45-62.

*I first presented material on evanescence in Dubrovnik in 2012, and most latterly in Warwick in 2014. Along the way, versions of this material found their way into talks in London, Paris, York, at Northwestern University and in Geneva. I'm immensely grateful to audiences on those occasions and, in particular, to Louise Richardson, Mohan Matthen, Mike Martin and Barry Smith (some critical points they raised have found their way into the thread of the argument though not always in the form first expressed). Guy Longworth, Andy Hamilton, and Craig French read previous versions of this paper - thank you! My co-editor Tom Crowther provided extremely detailed and insightful comments on numerous drafts (the dialectic has been shaped largely in response to his concerns, and the paper thereby owes a lot to his warm disagreement). Finally, for enlightening discussion of Anscombe, I'm indebted to my brilliant colleague and train companion, Rachael Wiseman.

${ }^{1}$ The Anscombe papers I refer to are her (1965) 'The Intentionality of Sensation: A Grammatical Feature' (IS), and (1976) 'The Subjectivity of Sensation' (SS)

2 See especially chapters 5 and 11.

${ }^{3}$ For the purposes of this paper, I simply take Thayer's assertion at face value. That is, I don't read into it any kind of commitment to experience being 'existence-presenting', where 'appearing to cease to exist' may involve experience failing to present this property.

${ }^{4}$ In this paper, I not trying to characterize the phenomenology of disappearance. Rather, I am trying to gesture at the kinds of structured visible appearances that, for a biologically-apt perceiver, may lead to the phenomenology that Thayer demonstrates and so, in such sensory contexts, warrant, as I claim, permissible uses of 'looks invisible'. With this explanatory aim in mind, there is no claim that being evanescent is usefully understood either as property of an object (though there are objects that may be apt to evanesce in certain conditions and at certain places) or as a property of an experience. See Soteriou (2013) for a discussion of disappearance. For a different treatment, see Farrenikova, this volume.

${ }^{5}$ See Travis (2015)

${ }^{6}$ Note Anscombe's caution: "The fact that we can use the concept of identity in connection with intentional objects should not lead us to think there is any sense in questions as to the kind of existence - the ontological status of intentional objects as such" (1965/1981, p.11)

${ }^{7}$ For discussion of this example, see Anscombe (1957/2000, p.25)

8 Practically speaking, this might also seem to be the case with Franco - would a perceiver call on another to look at something that she does not notice? The distinction comes out as follows: we can imagine a painting instructor calling on a trainee to pay attention to the colour of a particular patch of sky. The colour of the sky at a location is available for both to see. Thanks to Tom Crowther for pressing this point.

${ }^{9}$ By material object, Anscombe does not mean material objects in the sense of tables, planets, lumps of butter; the description "that debt of five dollars" has as its material object a particular debt owed.

10 T-junctions, in contrast, elicit the perception of an occluding surface.

11 For discussion see Newall (2015).

12 Thanks to Mohan Matthen for emphasizing this point. See Stevens M., and Merilaita S. (2011) for an introduction to the state of the art in field animal camouflage studies.

13 This is usually effected through matching the spatial phase of the surface coloration of the animal's body with that of its surroundings. Cott dedicates fifty pages to such disruption. 
${ }^{14}$ Even in the merely intentional case, say where a psychoanalyst asks her hallucinating patient "What do you see?" and where the intended use is intentional, the question, it might be said, has the material form. This is since the very practice of asking questions and giving responses only has meaning in the context of a shared human life that itself has a form and, of course, materiality (where this can extend to encompass such materially ideal goods as debts).

15 See, for instance, the helpful overview contained in Brogaard (2014) and Brogaard (2015).

${ }_{16}$ Generally, this taxonomising approach can be said to contrast with the Geachian/Anscombian approach whereby variation in use of an expression is revelatory of a certain structure in the exercise of the same concept.

17 This comes from an Encyclopedia entry on Nonsense by Annette Baier - her first published piece of work - and which Diamond cites.

18 Jackson's analyses ' $X$ looks blue to $S$ ' as 'There looks to $S$ to be something blue' which is equivalent to 'S immediately sees a blue sense-datum belonging to $X$ ' or ' $S$ immediately sees a blue sense-datum'. See Jackson (1977) ${ }^{19}$ I say 'read' since although Martin's work does invite the ontological objectivist reading I sketch, it need not be read this way. That is, one could deny the identification of 'looks' with basic visible properties, and insist that we maintain a resolutely grammatical grasp on what is in a look. For my part, I think that Martin's position is, in many respects, close to Anscombe's.

20 Some further gloss on SIM may be required. Since Martin may be read as identifying looks with the basic visible properties of objects, looks are not treated phenomenalistically. Nonetheless, he does grant that there is a kind of subjectivity that is implicit in our talk of the looks of things. This subjectivity is not the relativity that attends the more complex 'the coin looks elliptical to me'. Rather, it can be understood as complicit both at the level of the specification of the metric - this involves the operation 'getting the characteristic', which itself involves knowledge of the kind of appearance that the metric intensionally specifies - and it is implicated in the predicate of predicates and individuals SIM for we read this as visually striking one as looking relevantly similar. I leave aside consideration of what explains this capacity. For a critique of Martin's treatment, see Glüer (2013).

${ }^{21}$ For a dispositionalist treatment, see e.g. Genone (2014). Influential treatments that I do not consider are Breckenridge (2007) and Maund (1986) among others.

22 This position can be read as borrowing aspects from both the natural and Wittgentsteinean/Fregean positions. Since it is assumed that gist can be reported in oratio obliqua form, sometimes using different words (viz. what is reported is not merely that certain words were mentioned), it must be allowed that the content of the that-clause in the oratio obliqua formulation expresses a thought which is similar in gist to what the speaker thought, and which the that-clause reports. There is then, broadly speaking, such a thing as sameness of meaning of individual expressions, but this is established at the level of the use of sentences which express judgments (see Diamond 1991, p.109)

${ }^{23}$ For discussion of this example, see Anscombe (1957/2000, p.2).

24 Thanks to Rachael Wiseman for suggesting an application of the thick/thin contrast, familiar from discussion of ethical concepts, to the perceptual case.

25 This way of putting things was suggested to me a long time ago by Matt Nudds. A different way of conceptualising the same datum is to suggest that perfectly (though contingently) transparent things can 'hide' in empty regions.

${ }^{26}$ From http://www.nationalgeographic.com/animals/reptiles/g/green-iguana/ (last accessed 1 st September 2017)

${ }^{27}$ See Richardson (2010). On this view, in being aware of the boundaries of one's visual field, one can come to be aware of regions where, were visible material located there, it would be seen. Prima facie, evanescence is a counterexample.

28 A less substantive but related lesson is the following: We should not oppose the visible to the transparent or the see-through. 'Looking transparent' is not the same as 'looking invisible'. Perceptual transparency always involves seeing at least two surfaces in two distinct depth planes. When something 'looks invisible', in contrast, perception is single-fold (compare Mizrahi, this volume). 